\title{
SEED PRIMING WITH GLYCINE BETAINE IMPROVE SEED GERMINATION CHARACTERISTICS AND ANTIOXIDANT CAPACITY OF WHEAT (TRITICUM AESTIVUM L.) SEEDLINGS UNDER WATER-STRESS CONDITIONS
}

\author{
AhMED, N. - ZhANG, Y. - YU, H. - GABAR, A. - ZHOU, Y. - LI, Z. - ZHANG, M. ${ }^{*}$ \\ Engineering Research Center of Plant Growth Regulator, Ministry of Education College of \\ Agronomy and Biotechnology, China Agricultural University, Beijing 100193, China \\ (phone: (86)-1062733049) \\ *Corresponding author \\ e-mail:zmc1214@163.com
}

(Received $1^{\text {st }}$ Mar 2019; accepted $1^{\text {st }}$ May 2019)

\begin{abstract}
Water-stress is one of the most adversarial environmental constraints limiting wheat growth and productivity. Seed priming is a promising approach to alleviate the adverse effects of water-stress on seed germination and early seedling establishment. In the current study, we evaluated the effectiveness of Glycine-betaine (GB) to improve seed germination and early seedling establishment of Wheat (Cultivar: Jimai-22) under water-stress conditions. The current study was conducted at the Engineering Research Centre of Plant Growth Regulator, College of Agronomy and Biotechnology, China Agricultural University, Beijing, China, during the year 2018-19. Water-stress significantly reduced seed germination characteristics, shoot/root fresh weight and dry matter accumulation, and relative water content (RWC). Moreover, water-stress aggressively increased the production of Proline, soluble sugars, Hydrogen peroxide $\left(\mathrm{H}_{2} \mathrm{O}_{2}\right)$, and Malondialdehyde (MDA) and showed higher electrolyte leakage and reduced membrane stability. However, seed priming with GB significantly alleviated adversities of water-stress on seed germination characteristics and early seedling growth attributes; the effects were more pronounced with GB 50 and $100 \mathrm{mM}$ seed treatment. Seed priming with GB counteracted the overaccumulation of proline, soluble sugars, $\mathrm{H}_{2} \mathrm{O}_{2}$, and MDA content and increased membrane stability and reduced electrolyte leakage with higher activity of antioxidant enzymes under water-stress treatment. Water-stress tolerance augmented by GB priming might be related to higher antioxidant activity and reduced reactive oxygen species (ROS) accumulation and lipid peroxidation, eventually lower electrolyte leakage and higher membrane stability, all these salient features of GB enhanced survival capability of wheat seedlings under water-stress conditions. The study is a valuable validation for enhancing water-stress tolerance via GB priming, which is of broad-spectrum interest for sustainable agriculture production.
\end{abstract}

Keywords: seed treatment, Glycine betaine, seedling vigor, osmolyte accumulation, water-stress tolerance

\section{Introduction}

Water-stress is a serious agronomic problem worldwide and is one of the most important factors reducing crop productivity (Farooq et al., 2012; Li and Liu, 2016). Successful and uniform seed germination is essential for healthy plant growth and development to enhance productivity potential as well as the quality of crop production (Conrath et al., 2006; Cheng et al., 2018). Uneven and delayed seed germination often result in poor seedling establishment. Therefore, it is essential to enhance seed germination and seedling vigor under osmotically stressed conditions. Seed germination and emergence are the primary steps in successful seedling development and crop productivity. Seed germination is defined as a sequence of events that start with the imbibition of dry seeds and that terminate with the elongation of the embryonic radicle (Bewley, 1997; Wolny et al., 2018). 
Generally, seeds start the germination process under optimal environmental conditions (i.e., sufficient or optimal water, oxygen and temperature). However, seeds under sub-optimal conditions, such as water stress, salinity, and extreme temperatures, showed uneven germination and poor seedling development (Mahmood et al., 2009; Jisha et al., 2013; Nawaz et al., 2013; Hussain et al., 2016). Extensive research efforts have been carried out in order to improve the crop performance under water deficit conditions. Nevertheless, water deficit is still a major limitation to crop growth and productivity. Typically, seed germination and early seedling growth are less tolerant to environmental fluctuations as compared to mature plants. Thus, soil moisture stress during early growth may result in high mortality rates, leading to reduced crop performance (Chachar et al., 2016).

To enhance seed germination rate and seedling vigor under adverse environmental conditions. The pretreatment of seeds called seed priming is widely practiced in agriculture. Suitable priming treatment enhances seed germination and boosts seedling vigor in different crops. Research demonstrated that variety of chemicals shown potential to act under specific conditions as a defense priming agent against a range of different abiotic stresses (Beckers and Conrath, 2007), such chemicals includes: amino acids; Proline, Glycine-Betaine (Moustakas et al., 2011), hormones; Salicylic acid, Abscisic acid (Srivastava et al., 2010; Nazar et al., 2015), reactive oxygen-nitrogensulfur species (Seabra and Oliveira, 2016), mineral priming; Selenium, Calcium chloride (Iqbal et al., 2015) and even water; hydro-priming (Iqbal et al., 2015).

GB priming is an effective strategy to improve seed germination, emergence, and seedling growth of several crop plants, especially under stress conditions (Farooq et al., 2008; Atta et al., 2013; Zhang et al., 2014; Rakshit and Singh, 2018). GB could ameliorate the adversities of oxidative stress by detoxification of ROS both directly or by enhancing the activities of ascorbate peroxidase (APX), glutathione (GSH) and GSH/GSSG, Ascorbate (AsA), mono-dehydro-ascorbate reductase (MDHAR), dehydroascorbate reductase (DHAR), glutathione reductase (GR), glutathione peroxidase (GPX), catalase (CAT), and glyoxalase I (Gly I) in the different crops under adverse environmental conditions (Hasanuzzaman et al., 2014; Gupta and Thind, 2015). For example, Cheng et al. (2018) reported that GB priming increased the chilling stress tolerance of Cotton at the seedling stage, exhibited a higher net photosynthetic rate, improved antioxidant enzyme activity, and lower hydrogen peroxide content and less damage to the cell membranes. Water-stress significantly hindered seed germination and seedling growth, reduced starch metabolism, RWC, and increased cell electrolyte leakage. However, seed priming with GB improved the germination rate, root and shoot length, seedling fresh and dry weights, leaf and root scores, RWC, soluble sugars, and a-amylase activity as compared to unprimed seeds of Maize under chilling stress (Farooq et al., 2008). Similar improvements were also noted for Turfgrass under different stress conditions such as drought, salinity, and temperature (Zhang et al., 2014).

Seed priming has potential to promote uniform and synchronized seedling emergence and enhance the capability of seedlings to establish under unfavorable environmental conditions. Physiologically, seed priming strengthened the antioxidant activities of CAT, POD, SOD, and APX and as well as promoted the accumulation of compatible solutes including reducing sugar, proline, soluble sugars, free amino acids, and soluble proteins contents (Zhang et al., 2015). As a result, seed priming reduced lipid peroxidation and stabilized the cell membranes integrity, resulting in increased stress 
tolerance under water-deficit or excessive soil moisture environments (Zhang et al., 2015).

Seed priming with GB could play a significant role during germination and early seedling growth of wheat. Therefore, it is crucial that this method should be employed in wheat production to improve water-stress tolerance by seed priming with GB. In this study, we examined the effects of GB seed priming with different concentrations of GB to optimize suitable concentration and evaluate its effectiveness to improve wheat seed germination and seedlings development under water-stress conditions. We ensured that 50 to $100 \mathrm{mM}$ concentrations of GB for seed priming $12 \mathrm{~h}$ were more advantageous for uniform and synchronised seed germination and successful seedling growth. For further insight into the phenomenon, we investigated the activities of different antioxidant enzymes directly involved in detoxification of ROS, triggered by water-stress.

\section{Material And Methods}

\section{Growing conditions and treatment details}

This study was conducted at the Engineering Research Center of Plant Growth Regulator, College of Agronomy and Biotechnology, China Agricultural University, Beijing, China, during the year 2018-19. The present study was aimed to evaluate the effect of GB seed priming on wheat seed germination and early seedling growth. Wheat (Triticum aestivum L.) cultivar "Jimai-22" was used in the current study. Jimai-22 is an inbreed hexaploid wheat cultivar, which is mostly planted by the wheat farmers in North China Plan (Li et al., 2015). To eradicate contamination during seed priming, wheat seeds of uniform size were surface-sterilized with $3 \% \mathrm{NaClO}$ for 10 minutes. All the glassware and hydroponic solution used in this study were autoclaved before to use. The seed-priming treatments were hydro-priming (HP; distilled water), chemical priming (GB: 10, 25, 50 and $100 \mathrm{mM}$ ), and a non-primed control (NP) included for comparison. Wheat seeds were primed in the dark at $25^{\circ} \mathrm{C}$ for $12 \mathrm{~h}$ with constant gentle shaking in a mechanical shaker. The proportion of seed weight to volume of priming solution was maintained as (w/v) was 1:5 (Hussain et al., 2016). After $12 \mathrm{~h}$ of priming treatment, the primed seeds were washed thoroughly with deionized water for 4-5 times, to remove priming agent from the surface of the seeds. The primed seeds were surfacedried using blotting paper and placed to an air- drying oven at $25^{\circ} \mathrm{C}$ for $48 \mathrm{~h}$ to minimize the moisture content to $<10 \%$. The experiment was designed in Completely Randomized Design (CRD) with three replications. After achieving required seed moisture content, 20 seeds per replicate were placed in $12.5 \mathrm{~cm}$ Petri dish on a double layer of filter paper No.102, moistened with $10 \mathrm{ml}$ of distilled water considered as wellwater (control) or with $10 \mathrm{ml}$ of $10 \%$ PEG-6000 solution (water-stress). During the experiment, $10 \mathrm{ml}$ of autoclaved distilled water or $10 \%$ (w/v) PEG-6000 solution was added to each petridish after every $24 \mathrm{~h}$ to maintain constant moisture. The radicle protrusion at $1 \mathrm{~mm}$ was recorded as the criterion for germination (Guo et al., 2017). The experiment was conducted in a controlled room (Environmental Growth Chamber, China Agricultural University, Beijing), which was set to maintain $22 / 18^{\circ} \mathrm{C}$ (day/night), $60 \%$ relative humidity, $12-\mathrm{h}$ photoperiod, and $650 \mu \mathrm{molm}^{-2} \mathrm{~s}^{-1}$ photosynthetically active radiation at the canopy level. Seedlings kept for eight days under stressed and non-stressed conditions. Growing media solution was changed after every $48 \mathrm{~h}$; the number of seeds germinated after every $12 \mathrm{~h}$ was recorded and final germination percentage was calculated when there was no more germination in reach treatment 


$$
-8336 \text { - }
$$

(day-4). All the seedlings were harvested after eight days of planting, five seedlings from each replicate were used for the root and shoot fresh and dry weight measurements, while the rest of seedlings were wrapped in an aluminum foil and exposed to liquid nitrogen and saved to $-80^{\circ} \mathrm{C}$ for further biochemical studies.

\section{Seed germination characteristics}

The following germination characteristics were recorded according to AOSA (1983). Final germination $\%$

$$
(G)=\frac{\text { total seeds germinated }}{\text { total seeds planted }} \times 100
$$

Germination rate index

$$
(\mathrm{GRI})=\left(\frac{\mathrm{G} 1}{1}+\frac{\mathrm{G} 2}{2}+\frac{\mathrm{G} 3}{3}+\cdots \frac{\mathrm{Gi}}{\mathrm{i}}\right)
$$

where G1 is the germination percentage on day $1, \mathrm{G} 2$ is the germination percentage on day 2; and so on.

Seedling Vigour Index

$$
\text { (SVI) }=\text { shoot lenghth }+ \text { root length } \times \mathrm{G}
$$

\section{Root and shoot length measurement}

Fifteen seedlings from each treatment were randomly collected (five for each replicate) for the measurement of the root and shoot length (by using a Vernier caliper) at the $8^{\text {th }}$ day of planting.

\section{Plant growth and biomass accumulation}

For the measurement of fresh weight and dry matter accumulation, shoot, and root were separated and weighed for their fresh weight. The shoot/root dry weight was recorded in milligrams after drying in hot air oven (SANYO, Model, MOV-202, Japan) at $80^{\circ} \mathrm{C} \pm 5^{\circ} \mathrm{C}$ for 72 hours. All the related traits were recorded after eight days of planting.

\section{Relative water content (RWC)}

The RWC was calculated by using leaves from randomly selected plants; the leaves were cut into about one $\mathrm{cm}$ discs and weighed to get fresh weight (FW). Later these leaf discs were soaked in distilled water for $4 \mathrm{~h}$ and turgid weight (TW) was recorded, leaves discs were then dried in an oven till constant weight at $80^{\circ} \mathrm{C}$ to obtain the dry weight (DW). RWC was calculated as

$$
\mathrm{RWC} \%=\frac{F W-D W}{\mathrm{TW}-\mathrm{DW}} \times 100
$$

\section{Malondialdehyde (MDA) and Hydrogen peroxide $\left(\mathrm{H}_{2} \mathrm{O}_{2}\right)$ content}

Determination of lipid peroxidation in wheat seedlings was done by, Thiobarbituric acid (TBA) test, which determines MDA as an end product of lipid peroxidation (Heath 
and Packer, 1968). Plant material (500 mg) was homogenized in $5 \mathrm{ml}$ of $0.1 \%(\mathrm{w} / \mathrm{v})$ Trichloroacetic acid (TCA) solution. The homogenate was centrifuged at $10000 \times \mathrm{g}$ for $20 \mathrm{~min}$, and $0.75 \mathrm{ml}$ of the supernatant was added to $1.5 \mathrm{ml}$ of $0.5 \%(\mathrm{w} / \mathrm{v})$ TBA in $20 \%$ TCA. The mixture was incubated in boiling water for $30 \mathrm{~min}$, and then reaction stopped by placing the reaction tubes in an ice bath. Then the samples tubes were centrifuged at $10000 \times \mathrm{g}$ for $5 \mathrm{~min}$, and the absorbance of the supernatant was recorded at $532 \mathrm{~nm}$ by using UNICO UV-2800AH spectrophotometer (UNICO Instrument Co. Ltd., Shanghai). The value for non-specific absorption at $600 \mathrm{~nm}$ was subtracted. The following equation was used to calculate MDA concentration using its absorption coefficient $(\varepsilon)$ and expressed as $\mu \mathrm{mol}$ Malondialdehyde $\mathrm{g}^{-1}$ fresh weight:

$$
\mathrm{MDA}\left(\mu \mathrm{mol} g-^{1} \mathrm{FW}\right)=[(\mathrm{A} 532-\mathrm{A} 600) \times \mathrm{Vt} \times 1000 / \varepsilon] \times \mathrm{Wt} \quad(\mathrm{Eq} .5)
$$

where $\varepsilon$ is the specific extinction coefficient $\left(=155 \mathrm{mM} \mathrm{cm}^{-1}\right)$, Vt is the volume of total extract and Wt is the fresh weight of leaf sample, A600 and A532 is the absorbance at 600 and $532 \mathrm{~nm}$ wavelength.

The $\mathrm{H}_{2} \mathrm{O}_{2}$ concentration was determined according to Alexieva et al. (2001). $500 \mathrm{mg}$ of wheat seedlings (shoot) samples were homogenized in an ice bath with $5 \mathrm{ml}$ of $0.1 \%$ (w/v) TCA. The homogenate was centrifuged at $10000 \times \mathrm{g}$ for $20 \mathrm{~min}$, and $0.5 \mathrm{ml}$ of the supernatant was added to $0.5 \mathrm{ml}$ of $10 \mathrm{mM}$ potassium phosphate buffer $(\mathrm{pH} \mathrm{7.0)}$ and $1 \mathrm{ml}$ of 1 Molar potassium iodide (KI). The absorbency of the supernatant was recorded on Spectrophotometer at $390 \mathrm{~nm}$. The content of $\mathrm{H}_{2} \mathrm{O}_{2}$ was given on a standard curve.

\section{Electrolyte leakage, and membrane stability index}

Leaf membrane damage was estimated by the recording of electrolyte leakage (EL) as reported by Bajji et al. (2002) with slight modifications. Plant material (500 mg) washed with distilled water and then placed in $15 \mathrm{ml}$ test tubes with $10 \mathrm{ml}$ of deionized water and incubated for $4 \mathrm{~h}$ at $25^{\circ} \mathrm{C}$. Subsequently, the electrical conductivity (EC) of the samples (R1) was recorded on the EC meter (DDS-12A; Shanghai Kangyi Co., Ltd., Shanghai, China). The samples were then autoclaved at $120^{\circ} \mathrm{C}$ for 20 minutes, cooled at room temperature and the final conductivity (R2) was recorded on the EC meter. The EL was defined as follows:

$$
\mathrm{EL} \%=\frac{R 1}{\mathrm{R} 2} \times 100
$$

However, Membrane stability index (MSI) was calculated by using the following equation:

$$
\mathrm{MSI} \%=\frac{1-R 1}{\mathrm{R} 2} \times 100
$$

\section{Antioxidant enzymes extraction and assays}

Antioxidant enzymes extraction was performed as described in Seckin et al. (2010) with slight modifications. Shoots of wheat seedlings were collected at the $8^{\text {th }}$ day of planting, and immediately placed into liquid nitrogen, then stored at $-80^{\circ} \mathrm{C}$ until used. Approximately $500 \mathrm{mg}$ of leaf sample was rapidly extracted in a pre-chilled mortar on an ice bath with five $\mathrm{mL}$ of ice-cold $50 \mathrm{mM}$ sodium phosphate buffer $(\mathrm{pH} \mathrm{7.8)}$ 
containing $1 \mathrm{mM}$ disodium diammonium acetate (EDTA-Na $), 1 \%(\mathrm{w} / \mathrm{v}$ ) polyvinyl pyrrolidone (PVPP) and $10 \mathrm{mmol} / \mathrm{L}$ magnesium chloride. Samples were centrifuged at $12,000 \times \mathrm{g}$ for $25 \mathrm{~min}$, and the supernatant was used for the determination of antioxidant enzymes activities. Likewise, catalase (CAT, EC 1.11.1.6) activity was estimated by monitoring the initial rate of disappearance of $\mathrm{H}_{2} \mathrm{O}_{2}$ by using spectrophotometer at $240 \mathrm{~nm}$ wavelength according to Cakmak and Horst (1991). Meanwhile, the activity of superoxide dismutase (SOD, EC 1.15.1.1) was determined using the method of Xue et al. (2008). Thus, the peroxidase activity (POD, EC 1.11.1.7) was determined by the guaiacol oxidation method (Nakano and Asada, 1981).

\section{Osmolyte accumulation}

Free proline content in shoots of wheat seedlings was extracted with 3\% sulfosalicylic acid and centrifuged at $12,000 \times \mathrm{g}$. An aliquot was mixed with glacial acetic acid and acidic ninhydrin for 30 minutes at $100^{\circ} \mathrm{C}$. The reaction was terminated in an ice bath, and chromophore was extracted with five $\mathrm{mL}$ of toluene. The chromophorecontaining toluene was warmed to room temperature, and absorbance was recorded on a spectrophotometer at $520 \mathrm{~nm}$ (Bates et al., 1973).

Total soluble sugars were extracted from the shoots samples previously stored at $-80^{\circ} \mathrm{C} .500 \mathrm{mg}$ of shoot sample with $5 \mathrm{ml}$ distilled water incubated in hot-water bath at $100^{\circ} \mathrm{C}$ for 20 minutes, the extract were centrifuged at $12,000 \times \mathrm{g}$ for $10 \mathrm{~min}$; supernatant was transferred to $15 \mathrm{ml}$ tube, and again $5 \mathrm{ml}$ of distilled water was added into the sample tube and extraction was repeated, supernatants were collected together. The supernatant was mixed with anthrone reagent, heated for $7 \mathrm{~min}$, the reaction was terminated by placing reaction tubes in an ice bath for $10 \mathrm{~min}$ and the absorbance was recorded on Spectrophotometer at $625 \mathrm{~nm}$. Total soluble sugars content was recorded according to the method elaborated by Morris (1948) and expressed as $\mathrm{mg} \mathrm{g}^{-1}$ fresh weight.

\section{Statistical analysis}

Statistical analysis and data computations were made using Microsoft Excel 2016 (Microsoft Corporation, Redmond, WA, USA) and Statistix 8.1 (Analytical Software, Tallahassee, USA). Significantly different treatment means were separated using the least significant difference (LSD at 0.05) test.

\section{Results}

\section{Seed germination ability, synchronization and seedling characteristics}

The seed germination response was varied among different water-stress and priming treatments (Fig. 1). Water-stress significantly arrested seed germination. However, seeds primed with distilled water (HP) as well as with different concentrations of GB had better seed germination percentage as compared to NP seeds under well-water and water-stress conditions. The maximum final seed germination \% was recorded in seeds primed with GB 50 and $100 \mathrm{mM}$ and had 13\% higher seed germination \% as compare to non-primed (NP) seeds under well-water conditions. Whereas under water-stress, a similar trend was observed and GB had maximum seed germination of $80 \%$ as compared to NP seeds of only $64 \%$. 


$$
-8339 \text { - }
$$

The germination rate index presented in Fig. 1, was also affected by water-stress and priming treatments; the higher germination rate was noted in response to GB priming treatments followed by HP. However, NP showed least germination index both under well-water and water-stress conditions.

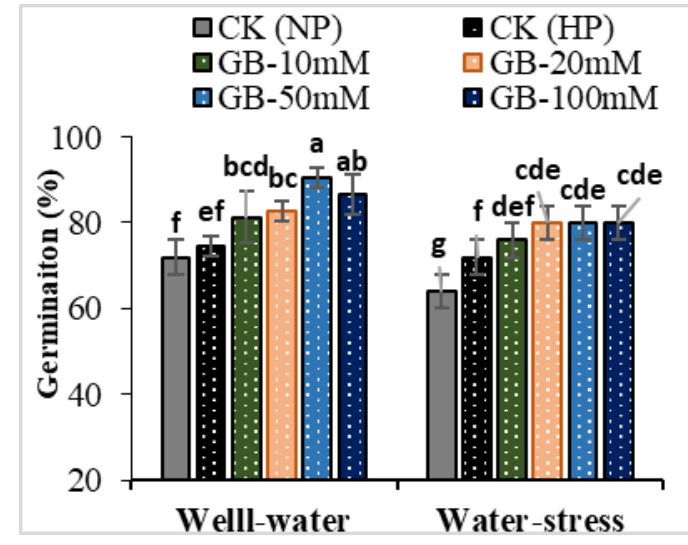

(a)

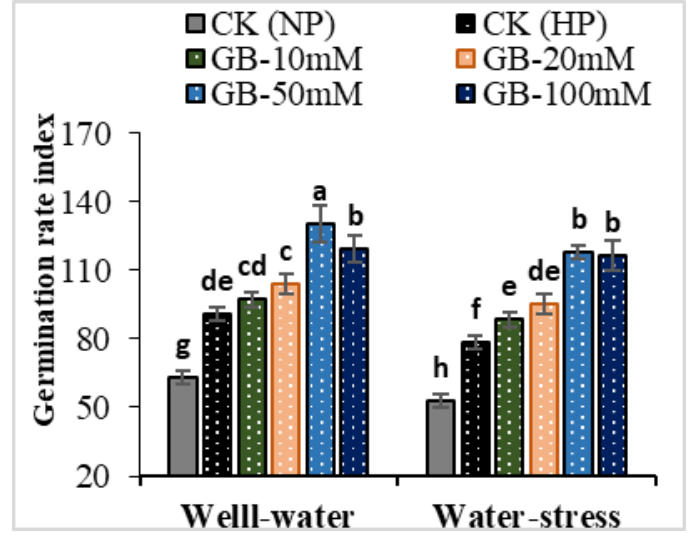

(b)

Figure 1. Effect of different seed priming treatments on seed germination (a) and germination rate index (b) of wheat seeds under well-water (non-stressed) and water-stress (PEG-10\%) condition. Control non-primed; $C K(N P)$, Control hydro-primed; $C K(H P)$, Glycine-betaine primed denotes $G B$. All values represent means \pm standard deviations $(S D)$ of three replicates. Bars showing the same letters are not significantly different at $P \leq 0.05$ as determined by LSD test

\section{Shoot, root length}

Under well-water conditions, the length of shoot and root was higher in primed seeds as compared to NP seeds. However, water-stress significantly affected seedling's shoot and root morphological characters (Figs. 2 and 3).

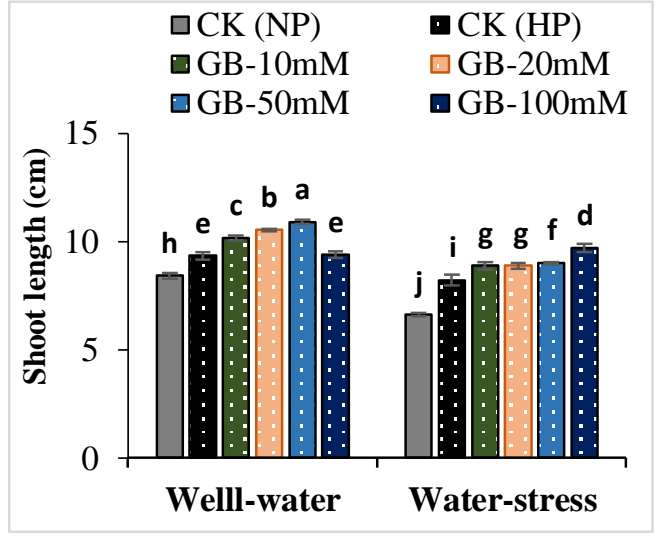

(a)

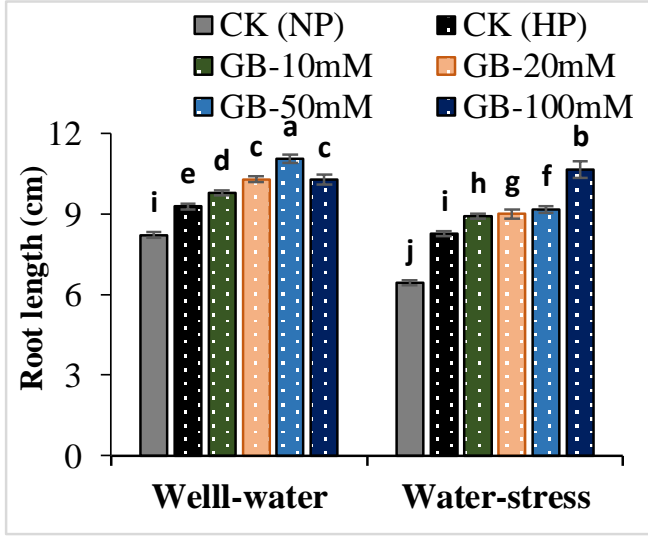

(b)

Figure 2. Effects of different seed priming treatments on shoot length (a) and root length $(b)$ of wheat seedlings under well-water and water-stress conditions. Control non-primed; $C K(N P)$, Control hydro-primed; $C K(H P)$, Glycine-betaine primed denotes GB. All values represent means \pm standard deviations (SD) of three replicates. Bars showing the same letters are not significantly different at $P \leq 0.05$ as determined by LSD test 
Under well-water treatment seeds primed with GB $50 \mathrm{mM}$ showed contrasting results in term of shoot and root length and showed 29 and 35\% higher shoot and root length as compared to NP seeds, however, HP seeds also had significant difference of 11 and $13 \%$ higher shoot and root length as compared to NP seeds under well-water treatment. Under water-stress, seeds primed with GB $100 \mathrm{mM}$ showed better seedling character in term of the shoot and root length and had 36 and $66 \%$ higher shoot and root length as compared to seedlings of NP seeds under water-stress conditions.

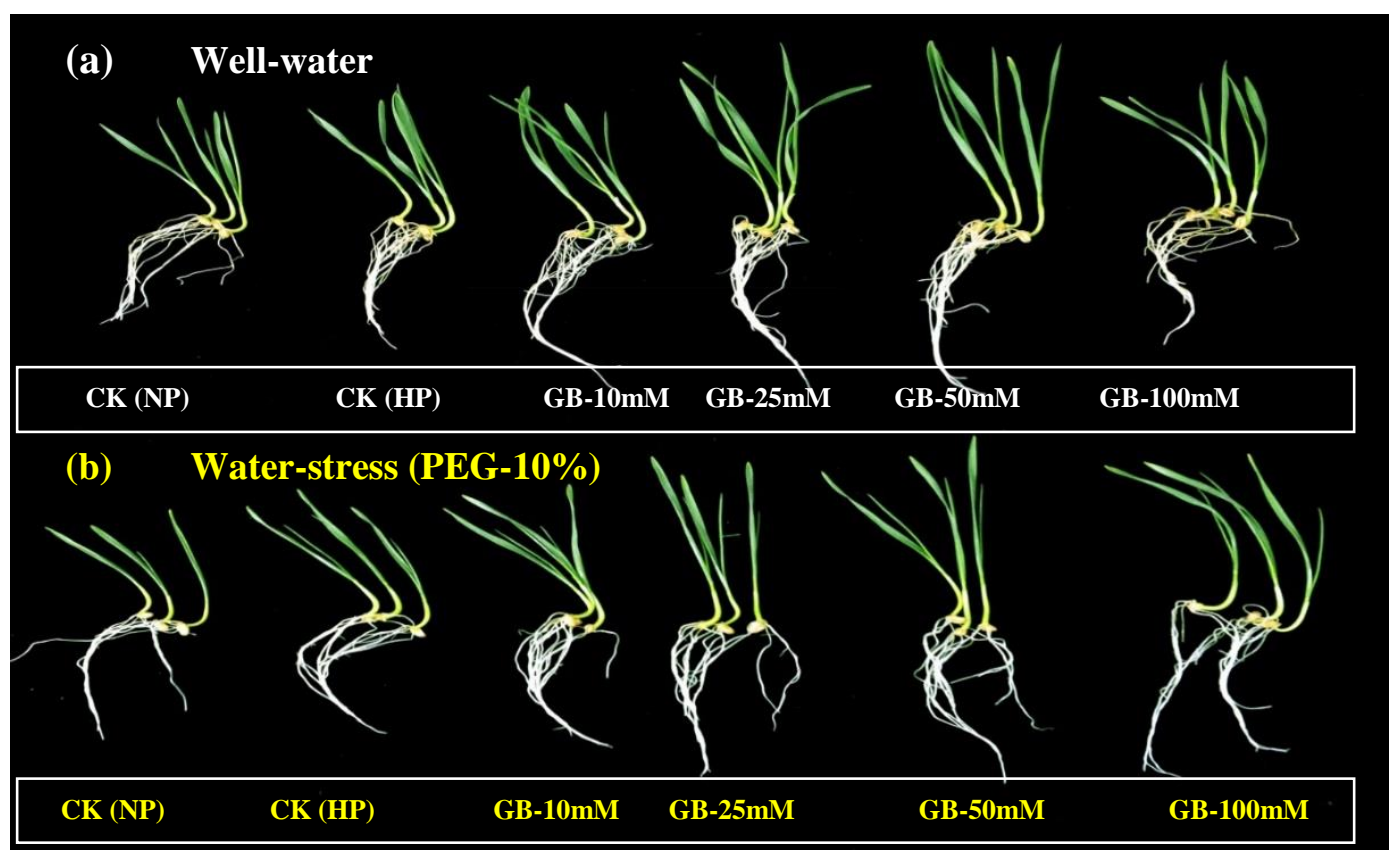

Figure 3. Effects of different seed priming treatments on morphological characteristics of wheat seedlings under well-water (a) and water-stress (PEG-10) (b) conditions. Control non-primed; $C K(N P)$, Control hydro-primed; $C K(H P)$, Glycine-betaine primed denotes GB

\section{Shoot, root fresh weight, and dry matter accumulation}

The response of wheat seedlings with respect to shoot and root fresh weight and dry matter accumulation were varied among different water and priming treatments (Fig. 4). The maximum shoot and root fresh weight were noted in 25 and $50 \mathrm{mM}$ of GB primed seeds as compared to rest of GB, HP and NP primed seeds, however, under water-stress conditions seeds primed with GB 50 and $100 \mathrm{mM}$ showed better performance as compared to seedlings of HP and NP treatments. Under the water-stress condition, NP demonstrated diminishing growth of the seedlings along with a significant decrease in dry weight of shoot and root (Fig. 4). Similar to seedling fresh weight, the dry weight of seedlings was also higher in 25 and $50 \mathrm{mM}$ GB primed seeds and under well-water treatment. However, GB 50 and $100 \mathrm{mM}$ were more effective under water-stress treatment and had higher dry matter accumulation as compared to HP and NP seeds.

\section{Seedling vigor index}

In the current study, water-stress significantly reduced the seedling vigor index as compared to the well-water treatment (Fig. 5). Irrespective of water-stress effects, seeds primed with GB significantly increase the seedling vigor index as compared to HP and 
NP seed treatments. The more prominent increase in seedling vigor was revealed by GB $100 \mathrm{mM}$ seed priming followed by 50,25 and $10 \mathrm{mM}$ under water-stress treatment.

\section{Shoot relative water content $(R W C)$}

There was a significant reduction in shoot RWC under water-stress as compared to well-water treatment (Fig. 5). Seed priming either with HP or GB considerably enhanced shoot RWC in water-stress treatment. The seedlings originating from the NP or HP seeds suffered a more significant decline in shoot RWC under water-stress treatment. However, seed priming with GB 50 and $100 \mathrm{mM}$ significantly increased 4.7 and $3.8 \%$ higher shoot RWC as compared to seedlings originated from NP seeds under water-stress treatment.

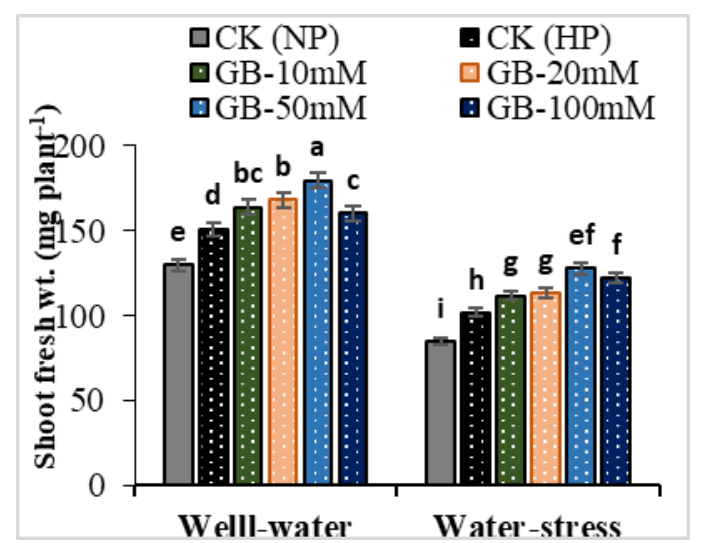

(a)

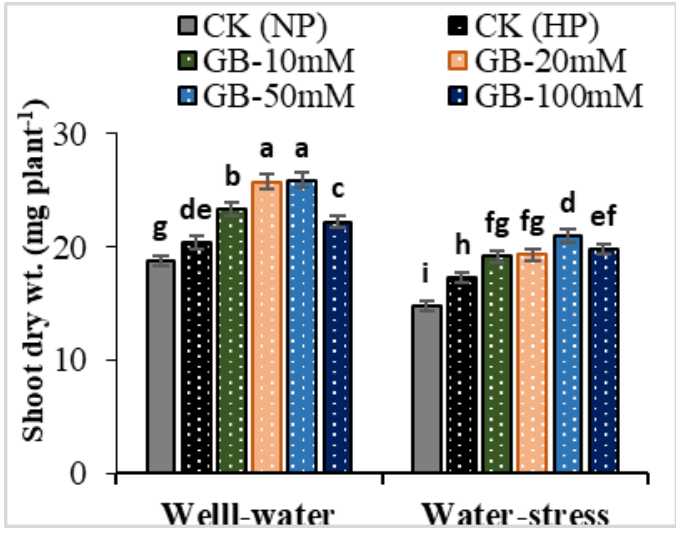

(c)

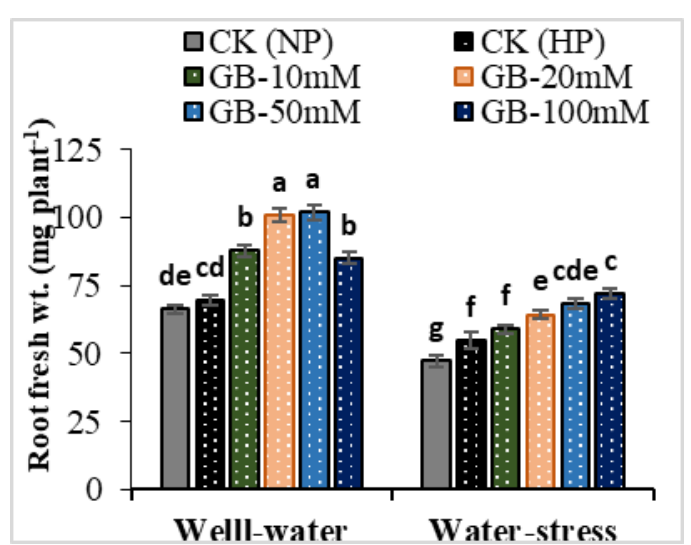

(b)

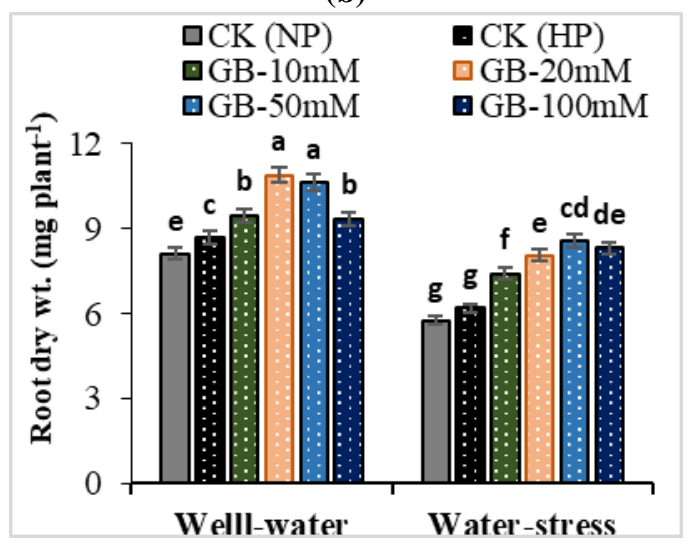

(d)

Figure 4. Effects of different seed priming treatments on the shoot and root fresh ( $a$ and $b$ ) and dry $(c$ and $d)$ weight of wheat seedlings grown under well-water and water-stress conditions.

Control non-primed; $C K(N P)$, Control hydro-primed; $C K(H P)$, Glycine-betaine primed denotes GB. All values represent means \pm standard deviations $(S D)$ of three replicates. Bars showing the same letters are not significantly different at $P \leq 0.05$ as determined by LSD test

\section{Lipid peroxidation and ROS accumulation}

The rate of lipid peroxidation was recorded in term of MDA accumulation, induced by PEG-stress was found to be dependent upon water-stress treatment (Fig. 6). Under well-water conditions, the MDA accumulation was almost similar in all wheat seedlings originated from either NP, HP or GB treated seeds. Upon exposure to PEG stress, the 
MDA accumulation was increased in all priming treatments; however, in the seedlings of GB primed seeds, the increase was lower than that of NP and HP seed priming treatments.

The response of wheat seedlings originated from NP, HP and GB primed seeds were varied among water-stress treatments, and exposure to water-stress all priming treatments showed a significant increase in $\mathrm{H}_{2} \mathrm{O}_{2}$ accumulation (Fig. 6). However, all the seeds either primed with different concentrations of GB or primed with distilled water (HP) showed lower accumulation of $\mathrm{H}_{2} \mathrm{O}_{2}$ and presented better performance as compared to seedlings of NP seeds under water-stress condition. The seedlings from the seeds treated with $100 \mathrm{mM}$ showed $18 \%$ lower $\mathrm{H}_{2} \mathrm{O}_{2}$ content compared with seedlings of NP seeds under water-stress treatment respectively.

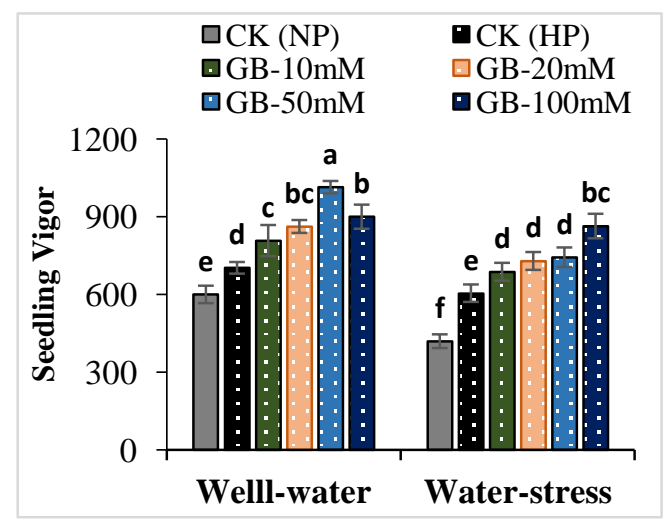

(a)

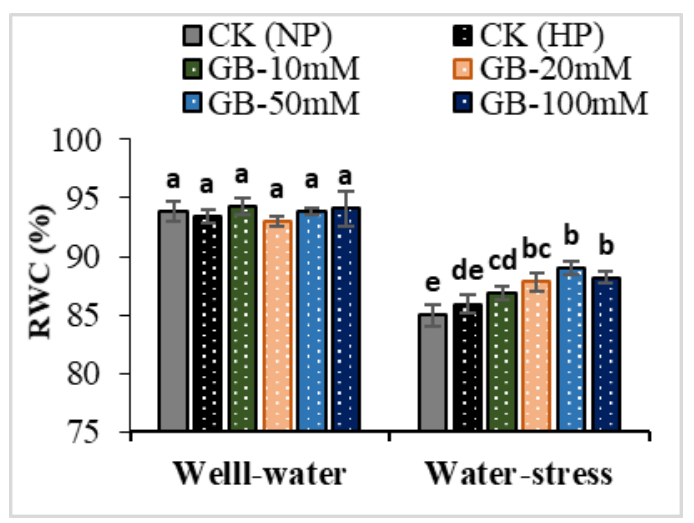

(b)

Figure 5. Effects of different seed priming treatments on seedlings vigor (a) and RWC (b) of wheat seedlings grown under well-water and water-stress conditions. Control non-primed; $C K$

$(N P)$, Control hydro-primed; $C K(H P)$, Glycine-betaine primed denotes GB. All values represent means \pm standard deviations $(S D)$ of three replicates. Bars showing the same letters are not significantly different at $P \leq 0.05$ as determined by LSD test

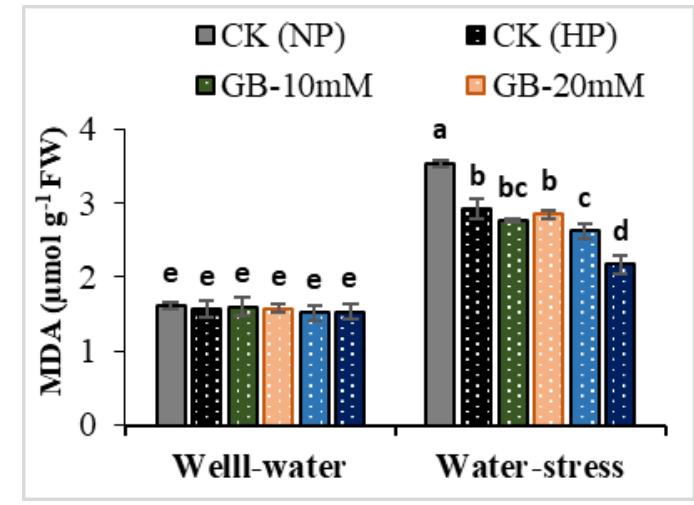

(a)

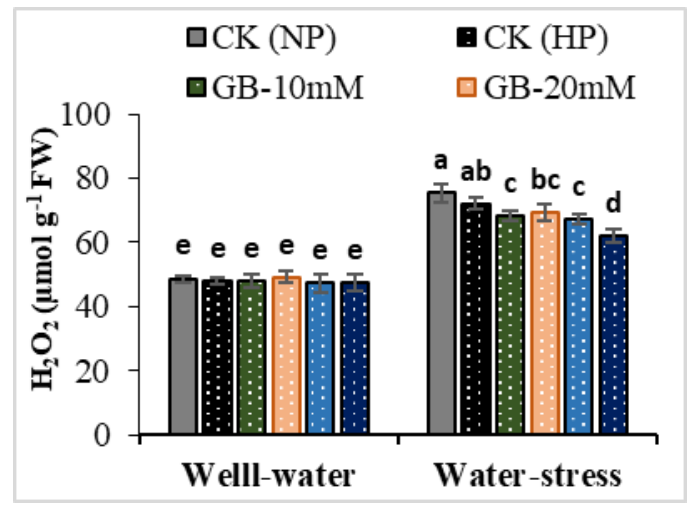

(b)

Figure 6. Effects of different seed priming treatments on $\mathrm{MDA}(a)$ and $\mathrm{H}_{2} \mathrm{O}_{2}(b)$ content in wheat seedlings grown under well-water and water-stress conditions. Control non-primed; $C K$

(NP), Control hydro-primed; $C K(H P)$, Glycine-betaine primed denotes GB. All values represent means \pm standard deviations $(S D)$ of three replicates. Bars showing the same letters are not significantly different at $P \leq 0.05$ as determined by LSD test 


\section{Membranes stability index and electrolyte leakage}

Cellular membrane stability is reciprocal to electrolyte leakage, the higher electrolyte leakage, the lower membrane stability. Membrane stability was not changed among different priming treatments and had lower electrolyte leakage under well-water conditions. However, under water-stress treatment cellular membrane stability was significantly reduced as elucidated from a significant increase in electrolyte leakage in the wheat seedling originated from either primed or non-primed seeds (Fig. 7).

The most damaging effects of water-stress were observed in wheat seedlings originated from NP seeds as increased electrolyte leakage and lower membrane stability index values under water-stress (Fig. 7). However, seed priming either with GB or with water significantly reduced electrolyte leakage and increased cellular membrane stability index under water-stress treatment. The most contrasting results were obtained by seed priming with GB 25 to $100 \mathrm{mM}$ concentrations and found lower electrolyte leakage and higher membrane stability index in wheat seeding originated from the seeds primed with high concentrations of GB and grown under water-stress conditions.

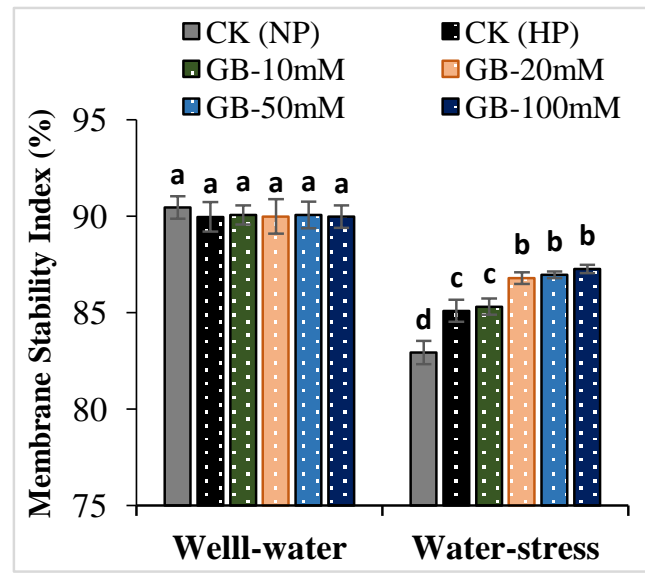

(a)

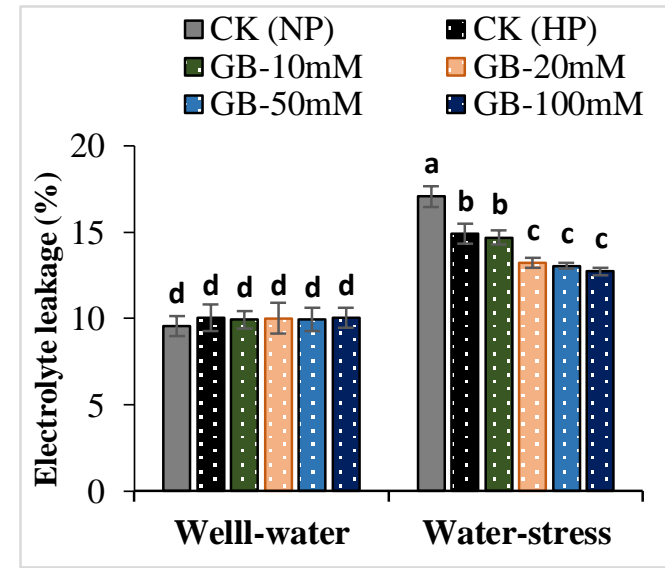

(b)

Figure 7. Effects of different seed priming treatments on membrane stability index (a) and electrolyte leakage $(b)$ of wheat seedlings grown under well-water and water-stress conditions.

Control non-primed; $C K(N P)$, Control hydro-primed; $C K(H P)$, Glycine-betaine primed denotes GB. All values represent means \pm standard deviations $(S D)$ of three replicates. Bars showing the same letters are not significantly different at $P \leq 0.05$ as determined by LSD test

\section{Activities of antioxidant enzymes}

The activities of antioxidant enzymes (CAT, POD and SOD) were significantly higher in osmotically stressed seedlings and significant variation was recorded among different priming treatments, whereas, under well-water conditions, the activities of CAT, POD and SOD in the seedlings of GB and HP primed seeds were almost similar to seedlings of NP seeds (Fig. 8). Under the water-stress condition, the CAT activity was increased significantly in the seedlings of GB 50 and $100 \mathrm{mM}$ primed seeds as compared to HP and NP seedlings. The activities of POD under water-stress, the seeding originated from GB 100 and $25 \mathrm{mM}$ primed seeds showed 19 and $14 \%$ higher POD activity as compared to seedlings of NP seeds. However, seedlings originated 
from 100mM GB and HP seeds showed $43 \%$ and $13 \%$ higher SOD activity as compared to seedlings of NP seeds under water-stress treatment (Fig. 8).

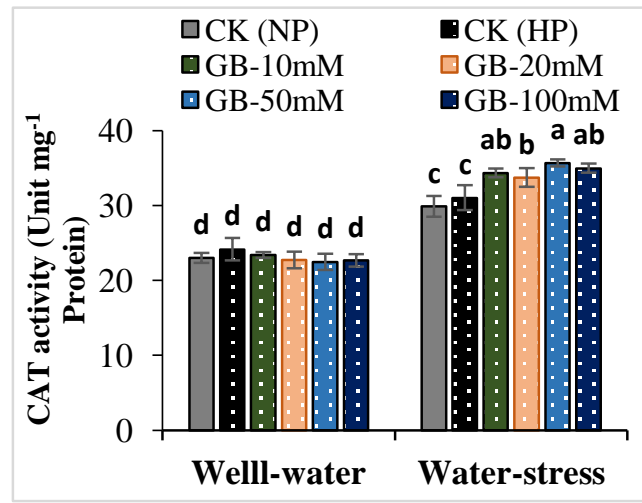

(a)

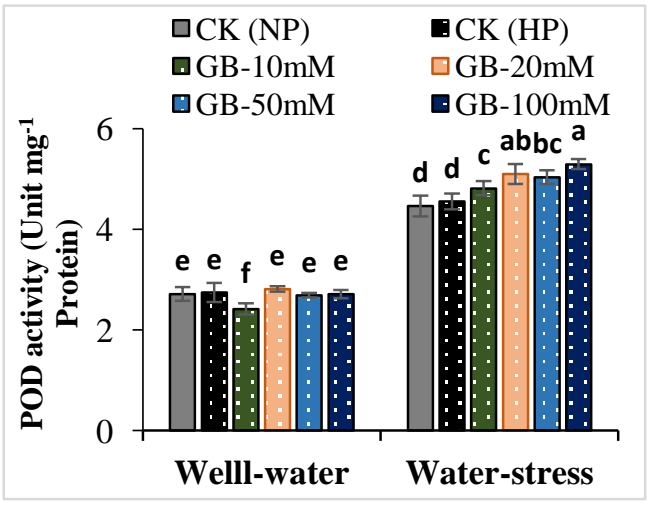

(b)

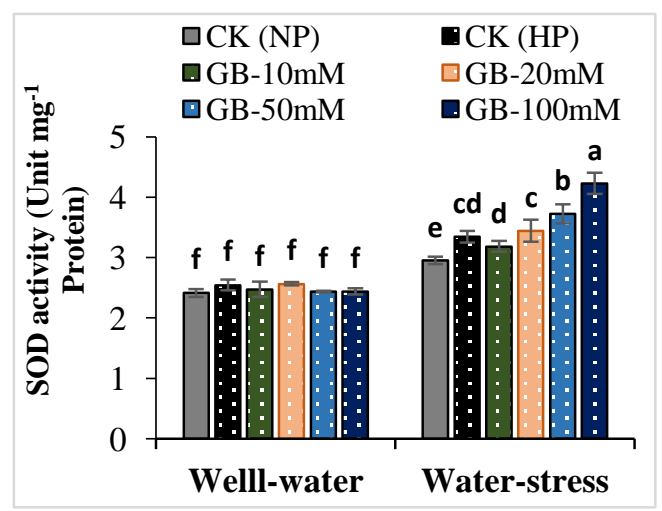

(c)

Figure 8. Effects of different seed priming treatments on the activities of antioxidant enzymes; catalase $(C A T)(a)$, Peroxidase $(P O D)(b)$ and superoxide dismutase $(S O D)(c)$, in wheat seedlings grown under well-water and water-stress conditions. Control non-primed; $C K(N P)$,

Control hydro-primed; $C K(H P)$, Glycine-betaine primed denotes GB. All values represent means \pm standard deviations (SD) of three replicates. Bars showing the same letters are not significantly different at $P \leq 0.05$ as determined by LSD test

\section{Osmolytes accumulation}

The results represent proline and soluble sugars contents in wheat seedlings under well-water and water-stress treatments are presented in Fig. 9. The accumulation of proline and soluble sugars significantly enhanced by water-stress; for instance, there was an approximately 6-fold increase in the proline content of water-stressed seedlings of NP seeds as compared to NP seedlings of well-water treatment. In addition, the proline content remarkably decreased with seed priming treatments. Moreover, 33 and $44 \%$ lower proline accumulation were recorded in the seedlings originated from GB 50 and $100 \mathrm{mM}$ primed seeds as compared to the seedlings of NP seeds under water-stress treatment. Similarly, the accumulation of soluble sugars content in wheat seedling was higher in water-stressed seedlings; however, more pronounced accumulation of soluble sugars was recorded in the seedlings of NP seeds. Seed priming significantly altered soluble sugars accumulation and 28 to $27 \%$ lower soluble sugars were accumulated in 
seedlings originated from GB 50 and $100 \mathrm{mM}$ primed seeds planted in water-stress treatment (Fig. 9).

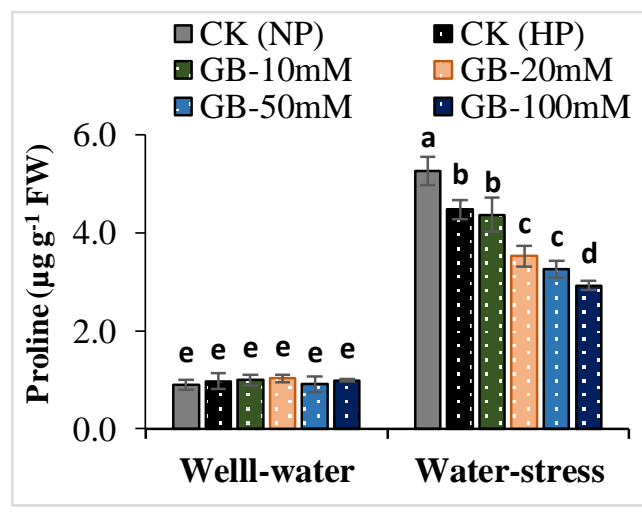

(a)

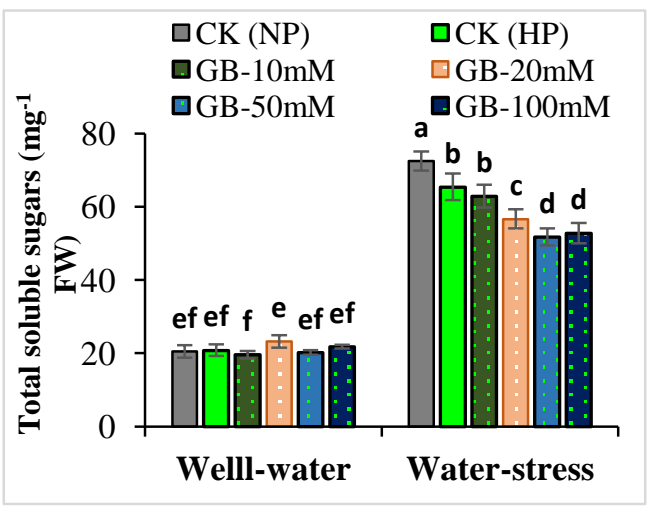

(b)

Figure 9. Effects of different seed priming treatments on proline (a), and total soluble sugars (b) content in wheat seedlings grown under-well-water and water-stress conditions. Control non-primed; $C K(N P)$, Control hydro-primed; $C K(H P)$, Glycine-betaine primed denotes GB. All values represent means \pm standard deviations $(S D)$ of three replicates. Bars showing the same letters are not significantly different at $P \leq 0.05$ as determined by LSD test

\section{Discussion}

Results of this study revealed that seed treatment with an appropriate agent and its concentration could invigorate wheat seeds, subsequent in greater germination ability and better seedling establishment and higher seedling fresh weight and dry matter accumulation under well-water and water deficit conditions (Figs. 1 to 4 ). In the current study, faster and more synchronized and uniform seed germination and seedlings emergence were recorded with seed priming, as indicated by higher germination \%, germination index (Fig. 1), shoot and root length (Fig. 2), fresh weight or dry matter accumulation (Fig. 4), and seedling vigor index (Fig. 5). Water-stress induced deleterious effects on seed germination and seedling growth were alleviated by seed treatment with GB, this improvement in synchronized seed germination and better seedlings establishment could be attributed from higher antioxidant activity and Maintainance of cellular membrane integrity. Our results are in agreement with the previous finding with Safflower, cotton, Turfgrass, and Wheat (Zhang et al., 2014; Salama et al., 2015; Alasvandyari et al., 2017; Cheng et al., 2018). Uniform and synchronized seed germination and early seedling establishment are the most critical stages for any crop. Water deficit may severely reduce seed germination capability, uniformity and dry matter accumulation (Jisha et al., 2013; Nawaz et al., 2013; Hussain et al., 2016). Consequently, the advantages of seed priming may be more helpful under sub-optimal soil water conditions compared with more favorable soil moisture conditions (Farooq et al., 2008; Mahmood et al., 2009; Zhang et al., 2014).

Water-stress induced growth decline has been previously reported by many researchers in different crops: Turfgrass (Zhang et al., 2014), Rice (Farooq et al., 2008) Sorghum (Zhang et al., 2015) and Wheat (Nawaz et al., 2013; Guo et al., 2017). Waterstress-induced reduction in plant growth and development is mainly attributed to a reduction in plant water potential, leaf RWC, photosynthesis and dry matter 
accumulation (Farooq et al., 2012). Our findings revealed that inhibitory effects of water-stress could be ameliorated by seed priming with GB appropriate concentration, our results demonstrated that seedling originated from seeds, primed with GB 50 and $100 \mathrm{mM}$ had better shoot RWC under water-deficit conditions and had the ability to reduce adversities of water-stress (Fig. 5). The decline in RWC showed a loss of turgor, which restricted water availability necessary for proper plant growth and development. Water-stress tolerance is substantially associated with tissue water potential and antioxidant system, exogenous application of GB significantly reduced adversities of water-stress in seedlings of fine grain aromatic rice and improved leaf water potential and had higher antioxidant activity and better photosynthetic ability under waterdeprived conditions (Farooq et al., 2008; Wani et al., 2013).

The cellular membrane stability was significantly affected by the overproduction of $\mathrm{H}_{2} \mathrm{O}_{2}$, and MDA content, which elucidated from the higher release of electrolytes from the cells under water-stress conditions. Furthermore, water-stress stimulated overproduction of $\mathrm{H}_{2} \mathrm{O}_{2}$ and MDA content in wheat seedlings (Fig. 6) represents a wellknown indicator of oxidative stress. However, seed priming with GB alleviated adversities of water-stress, which were manifested in term of substantially improved membrane stability index, as noted from lower electrolyte leakage (Fig. 7) and reduced $\mathrm{H}_{2} \mathrm{O}_{2}$ and MDA production. Higher ion leakage and MDA production are considered as indicators of oxidative stress (Mahajan and Tuteja, 2005; Farooq et al., 2012). The oxidative stress often arises from the overaccumulation of ROS, especially $\mathrm{H}_{2} \mathrm{O}_{2}$. Overproduction of $\mathrm{H}_{2} \mathrm{O}_{2}$ is toxic to cellular structure and macromolecules, impairing normal cellular activities (Das and Roychoudhury, 2014; Mittler, 2017). The overproduction of ROS in plants is managed by a variety of antioxidant enzymes and lipids and water-soluble macromolecules. Of these antioxidant enzymes (CAT, POD, and SOD) are the key components of ROS scavenging mechanism under oxidative stress conditions (Das and Roychoudhury, 2014; Lou et al., 2015; Xu et al., 2018). Our results suggested that the activities of antioxidant enzymes significantly triggered in wheat seedling originated from the seeds treated with GB (Fig. 8). This increase in activities of antioxidant enzymes and reduced ROS mediated injuries in wheat seedlings as evident from the association between $\mathrm{H}_{2} \mathrm{O}_{2}$ and MDA and antioxidant enzymes system under water-stress but not under well-water conditions.

It is well-established phenomena that proline and soluble sugars content in plant tissues enhanced by a variety of environmental stress including water-stress (He et al., 2011; Wei et al., 2015). Accumulations of these osmolytes in maize hybrids were increased with the severity of drought stress (Anjum et al., 2017). Water-stress significantly triggered the accumulation of proline and soluble sugars in this study (Fig. 9). Our results revealed that seed priming with GB reduced overproduction of proline and soluble sugars under water-stress. The effects of GB seed priming on proline accumulation under water can be interpreted based on the argument that higher accumulation of endogenous proline does not contribute to the osmotic adjustment in plants under water-stress conditions (Borgo et al., 2015). Lower accumulation of endogenous proline in wheat seedlings are also reported in GB primed seeds under salinity stress (Salama et al., 2015). Moreover, higher accumulation of soluble sugars adversely affects plant physiological and biochemical activities in a concentrationdependent manner (Aldesuquy et al., 2012; Sami et al., 2016). 


\section{Conclusion}

The results of the present study elucidated that the seed priming with GB did not simply accelerated germination-related processes but was also involved in other specific mechanisms that improved the seedling vigor and allowed the wheat seedlings to cope with the oxidative stress induced by water-stress. Increase in activities of antioxidants as governed by GB based seed priming can protect the degradation of enzymes from water- stress-induced ROS production and maintained cellular membranes stability. In addition to protecting from oxidative stress, GB seed priming was also involved in regulation of endogenous accumulation of proline and soluble sugars, RWC and antioxidant system in wheat seedlings, which may also be a remarkable demonstration of enhanced seed germination characteristics and seedling vigor under stressful environment.

Acknowledgements. This research was supported by National Key Research and Development Program of China (Grant No. 2017YFD0300410), and Introduction of International Advanced Agricultural Science and Technology Program of Ministry of Agriculture (Grant No. 2011-G19).

\section{REFERENCES}

[1] Alasvandyari, F., Mahdavi, B., Hosseini, S. M. (2017): Glycine betaine affects the antioxidant system and ion accumulation and reduces salinity-induced damage in safflower seedlings. - Archives of Biological Sciences 69(1): 139-147.

[2] Aldesuquy, H. S., Abbas, M. A., Hamed, S. A. A., Elhakem, A. H., Alsokari, S. S. (2012): Glycine betaine and salicylic acid induced modification in productivity of two different cultivars of wheat grown under water stress. - Journal of Stress Physiology \& Biochemistry 8(2): 72-89.

[3] Alexieva, V., Sergiev, I., Mapelli, S., Karanov, E. (2001): The effect of drought and ultraviolet radiation on growth and stress markers in pea and wheat. - Plant, Cell and Environment 24(12): 1337-1344.

[4] Amedea, B., Seabra, C., Oliveira, H. (2016): How nitric oxide donors can protect plants in a changing environment: what we know so far and perspectives. - AIMS Molecular Science 3(4): 692-718.

[5] Anjum, S. A., Ashraf, U., Tanveer, M., Khan, I., Hussain, S., Shahzad, B., Zohaib, A., Abbas, F., Saleem, M. F., Ali, I., Wang, L. C. (2017): Drought induced changes in growth, osmolyte accumulation and antioxidant metabolism of three maize hybrids. - Frontiers in Plant Science 08: 1-12.

[6] AOSA (1983): Seed Vigour Testing Handbook. USA: Contribution, Association of Official Seed Analysis and SCST. - Available at: https://www.analyzeseeds.com/product/ seed-vigor-testing-handbook-2017/ (Accessed: 19 February 2019).

[7] Atta, B. M., Mahmood, T., Trethowan, R. M. (2013): Relationship between root morphology and grain yield of wheat in north-western NSW, Australia. - Australian Journal of Crop Science 7(13): 2108-2115.

[8] Bajji, M., Kinet, J. M., Lutts, S. (2002): The use of the electrolyte leakage method for assessing cell membrane stability as a water stress tolerance test in durum wheat. - Plant Growth Regulation 36(1): 61-70.

[9] Bates, L. S., Waldren, R. P., Teare, I. D. (1973): Rapid determination of free proline for water-stress studies. - Plant and Soil 39(1): 205-207.

[10] Beckers, G. J., Conrath, U. (2007): Priming for stress resistance: from the lab to the field. - Current Opinion in Plant Biology 10(4): 425-431.

[11] Bewley, J. D. (1997): Seed Germination and Dormancy. - The Plant cell 9(7): 1055-1066. 
[12] Borgo, L., Marur, C. J., Vieira, L. G. E. (2015): Effects of high proline accumulation on chloroplast and mitochondrial ultrastructure and on osmotic adjustment in tobacco plants. - Acta Scientiarum. Agronomy 37(2): 191-199.

[13] Cakmak, I., Horst, W. J. (1991): Effect of aluminium on lipid peroxidation, superoxide dismutase, catalase, and peroxidase activities in root tips of soybean (Glycine max). Physiologia Plantarum 83(3): 463-468.

[14] Chachar, M. H., Chachar, N. A., Chachar, Q., Mujtaba, S. M., Chacahr, S., Chachar, Z. (2016): Physiological Characterization of Six Wheat genotypes for drought tolerance. International Journal of Research - Granthaalayah 4(2): 184-196.

[15] Cheng, C., Pei, L. M., Yin, T. T., Zhang, K. W. (2018): Seed treatment with glycine betaine enhances tolerance of cotton to chilling stress. - The Journal of Agricultural Science: 1-10.

[16] Conrath, U., Beckers, G. J. M., Flors, V., García-Agustín, P., Jakab, G., Mauch, F., Newman, M.-A., Pieterse, C. M. J., Poinssot, B., Pozo, M. J., Pugin, A., Schaffrath, U., Ton, J., Wendehenne, D., Zimmerli, L., Mauch-Mani, B. (2006): Priming: getting ready for battle. - Molecular Pant-Microbe Interactions 19(10): 1062-1071.

[17] Das, K., Roychoudhury, A. (2014): Reactive oxygen species (ROS) and response of antioxidants as ROS-scavengers during environmental stress in plants. - Frontiers in Environmental Science 2: 1-13.

[18] Farooq, M., Aziz, T., Hussain, M., Rehman, H., Jabran, K., Khan, M. B. (2008): Glycinebetaine improves chilling tolerance in hybrid maize. - Journal of Agronomy and Crop Science 194(2): 152-160.

[19] Farooq, M., Basra, S. M. A., Wahid, A., Cheema, Z. A., Cheema, M. A., Khaliq, A. (2008): Physiological role of exogenously applied glycinebetaine to improve drought tolerance in fine grain Aromatic Rice (Oryza sativa L.). - Journal of Agronomy and Crop Science 194: 325-333.

[20] Farooq, M., Hussain, M., Wahid, A., Siddique, K. H. M. (2012): Drought stress in plants: An overview. - In: Aroca, R. (ed.) Plant responses to drought stress: 1-33.

[21] Guo, Q., Wang, Y., Zhang, H., Qu, G., Wang, T., Sun, Q., Liang, D. (2017): Alleviation of adverse effects of drought stress on wheat seed germination using atmospheric dielectric barrier discharge plasma treatment. - Scientific Reports 7(1): 1-14.

[22] Gupta, N., Thind, S. K. (2015): Improving photosynthetic performance of bread wheat under field drought stress by foliar applied glycine betaine. - Journal of Agricultural Science and Technology 17(1): 75-86.

[23] Hasanuzzaman, M., Alam, M. M., Rahman, A., Hasanuzzaman, M., Nahar, K., Fujita, M. (2014): Exogenous proline and glycine betaine mediated upregulation of antioxidant defense and glyoxalase systems provides better protection against salt-induced oxidative stress in two rice (Oryza sativa L.) varieties. - BioMed research international 2014: 1-17.

[24] He, C., Zhang, W., Gao, Q., Yang, A., Hu, X., Zhang, J. (2011): Enhancement of drought resistance and biomass by increasing the amount of glycine betaine in wheat seedlings. Euphytica 177(2): 151-167.

[25] Heath, R. L., Packer, L. (1968): Photoperoxidation in isolated chloroplasts. - Archives of Biochemistry and Biophysics 125(1): 189-198.

[26] Hussain, S., Khan, F., Cao, W., Wu, L., Geng, M. (2016): Seed priming alters the production and detoxification of reactive oxygen intermediates in rice seedlings grown under sub-optimal temperature and nutrient supply. - Frontiers in plant science 7(4): 1-13

[27] Iqbal, M., Hussain, I., Liaqat, H., Ashraf, M. A., Rasheed, R., Rehman, A. U. (2015): Exogenously applied selenium reduces oxidative stress and induces heat tolerance in spring wheat. - Plant Physiology and Biochemistry 94: 95-103.

[28] Jisha, K. C., Vijayakumari, K., Puthur, J. T. (2013): Seed priming for abiotic stress tolerance: an overview. - Acta Physiologiae Plantarum 35(5): 1381-1396. 
[29] Li, Q., Bian, C., Liu, X., Ma, C., Liu, Q. (2015): Winter wheat grain yield and water use efficiency in wide-precision planting pattern under deficit irrigation in North China Plain. - Agricultural Water Management 153: 71-76.

[30] Li, X., Liu, F. (2016): Drought stress memory and drought stress tolerance in plants: Biochemical and molecular basis. - In: Drought stress tolerance in plants, Vol 1. Switzerland 2016: 616.

[31] Lou, Y., Yang, Y., Hu, L., Liu, H., Xu, Q. (2015): Exogenous glycinebetaine alleviates the detrimental effect of Cd stress on perennial ryegrass. - Ecotoxicology 24(6): 13301340 .

[32] Mahajan, S., Tuteja, N. (2005): Cold, salinity and drought stresses: An overview. Archives of Biochemistry and Biophysics 444(2): 139-158.

[33] Mahmood, T., Ashraf, M., Shahbaz, M. (2009): Does exogenous application of glycinebetaine as a pre-sowing seed treatment improve growth and plants grown under water deficit conditions? - Pakistan Journal of Botany 41(3): 1291-1302.

[34] Mittler, R. (2017): ROS Are Good. - Trends in Plant Science 22(1): 11-19.

[35] Morris, D. L. (1948): Quantitative determination of carbohydrates with dreywood's Anthrone reagent. - Science 107(2775): 254-255.

[36] Moustakas, M., Ilektra, S., Kouna, T., Antonopoulou, C. I., Therios, I. (2011): Exogenous proline induces soluble sugar accumulation and alleviates drought stress effects on photosystem II functioning of Arabidopsis thaliana leaves. - Plant Growth Regulation 65(2): 315-325.

[37] Nakano, Y., Asada, K. (1981): Hydrogen peroxide is scavenged by ascorbate-specific peroxidase in spinach chloroplasts. - Plant and Cell Physiology 22(5): 867-880.

[38] Nawaz, F., Ashraf, M. Y., Ahmad, R., Waraich, E. A. (2013): Selenium (Se) seed priming induced growth and biochemical changes in wheat under water deficit conditions. - Biological Trace Element Research 151(2): 284-293.

[39] Nazar, R., Umar, S., Khan, N. A., Sareer, O. (2015): Salicylic acid supplementation improves photosynthesis and growth in mustard through changes in proline accumulation and ethylene formation under drought stress. - South African Journal of Botany 98: 84-94.

[40] Rakshit, A., Singh, H. B. (2018): Advances in Seed Priming. - $1^{\text {st }}$ edition, Singapore: Springer Singapore.

[41] Salama, K. H. A., Mansour, M. M. F., Al-Malawi, H. A. (2015): Glycinebetaine priming improves salt tolerance of wheat. - Biologia (Poland) 70(10): 1334-1339.

[42] Sami, F., Yusuf, M., Faizan, M., Faraz, A., Hayat, S. (2016): Role of sugars under abiotic stress. - Plant Physiology and Biochemistry 109: 54-61.

[43] Seckin, B., Turkan, I., Sekmen, A. H., Ozfidan, C. (2010): The role of antioxidant defense systems at differential salt tolerance of Hordeum marinum Huds. (sea barleygrass) and Hordeum vulgare L. (cultivated barley). - Environmental and Experimental Botany 69(1): 76-85.

[44] Srivastava, A. K., Lokhande, V. H., Patade, V. Y., Suprasanna, P., Sjahril, R., D’Souza, S. F. (2010): Comparative evaluation of hydro-, chemo-, and hormonal-priming methods for imparting salt and PEG stress tolerance in Indian mustard (Brassica juncea L.). - Acta Physiologiae Plantarum 32(6): 1135-1144.

[45] Wani, S. H., Singh, N. B., Haribhushan, A., Mir, J. I. (2013): Compatible solute engineering in plants for abiotic stress tolerance - Role of glycine betaine. - Current Genomics 14: 157-165.

[46] Wei, L., Wang, L., Yang, Y., Liu, G., Wu, Y., Guo, T., Kang, G. (2015): Abscisic acid increases leaf starch content of polyethylene glycol-treated wheat seedlings by temporally increasing transcripts of genes encoding starch synthesis enzymes. - Acta Physiologiae Plantarum 37(10): 1-6.

[47] Wolny, E., Betekhtin, A., Rojek, M., Braszewska-Zalewska, A., Lusinska, J., Hasterok, R. (2018): Germination and the early stages of seedling development in brachypodium distachyon. - International Journal of Molecular Sciences 19(10): 1-14. 
[48] Xu, Z., Sun, M., Jiang, X., Sun, H., Dang, X., Cong, H., Qiao, F. (2018): Glycinebetaine biosynthesis in response to osmotic stress depends on jasmonate signaling in Watermelon suspension cells. - Frontiers in plant science 9: 1-14.

[49] Xue, G. P., McIntyre, C. L., Glassop, D., Shorter, R. (2008): Use of expression analysis to dissect alterations in carbohydrate metabolism in wheat leaves during drought stress. Plant Molecular Biology 67(3): 197-214.

[50] Zhang, Q., Rue, K., Mueller, J. (2014): The effect of glycinebetaine priming on seed germination of six turfgrass species under drought, salinity, or temperature stress. HortScience 49(11): 1454-1460.

[51] Zhang, F., Yu, J., Johnston, C. R., Wang, Y., Zhu, K., Lu, F., Zhang, Z., Zou, J. (2015): Seed priming with polyethylene glycol induces physiological changes in sorghum (Sorghum bicolor L. moench) seedlings under suboptimal soil moisture environments. PLoS ONE 10(10): 1-15. 